\title{
Knowledge about Novel Coronavirus (COVID-19) among health-care workers working at a Secondary Care Hospital.
}

\author{
1. MBBS \\ Research Officer \\ College of Ophthalmology and \\ Allied Vision Sciences Mayo Hospital. \\ 2. MBBS \\ Senior Cardiologist \\ Ghulam Muhammd Mahar Medical \\ College (GMMMC) Hospital \\ 3. DPT \\ Lecturer \\ Institute of Physical Medicine and \\ Rehabilitation \\ Dow University of Health Sciences. \\ 4. MBBS \\ Lecturer Physiology \\ Dow University of Health Sciences \\ 5. MBBS, M.Phil \\ Assistant Professor Community \\ Medicine \\ Karachi Medical and Dental College \\ 6. MBBS \\ Medical Officer Pediatrics \\ Ruth K M Pfau Civil Hospital. \\ 7. MBBS \\ Resident Medical Officer Medicine \\ Naz Memorial Hospital. \\ Correspondence Address: \\ Dr. Anas Bin Tariq \\ Department of Medicine \\ Naz Memorial Hospital \\ Karachi, Sindh, Pakistan \\ anastariq93@gmail.com
}

Article received on:

20/07/2020

Accepted for publication:

$19 / 09 / 2020$

\section{INTRODUCTION}

In the month of December 2019, novel coronavirus (COVID-19) was first observed in China's city of Wuhan, Hubei province amongst cluster of patients presenting with an unidentified variety of viral pneumonia. ${ }^{1}$ The common history in the patients was the visit of sea food market in the city. After assessment of patients for viral pneumonia through clinical examinations and laboratory testing of broncho-alveolar lavage fluid through special genomic testing, cell cultures and polymerase chain reaction (PCR). ${ }^{2}$ The viral organism which was isolated from the samples was detected as genus beta-coronavirus, being placed along the other Middle East Respiratory Syndrome (MERS) and Severe Acute Respiratory Syndrome (SARS). ${ }^{3}$
The virus spread to international countries like wild fire in less than a month from the first date of identification, especially because of the ability of virus to be transmitted through close human to human contacts. The termed COVID-19 was named as 'Corona Virus Disease-2019' and declared as a Public Health Emergency of international concerns by the World Health Organization (WHO) as of $1^{\text {st }}$ February $2020 .{ }^{4}$

The first global outbreak of SARS, a betacoronavirus was reported in July 2003 and was contained by 2004 and ever-since 2004 there were no outbreaks or any known case of SARS that were reported. ${ }^{5}$ Post SARS emergence was followed by MERS, which was the second coronavirus which resulted in major health crisis 
to public health globally. The emerging center was the Kingdom of Saudi Arabia, in 2012 where a 60-year old male was reported with severe pneumonia. Only a single case was reported then, however the outbreak did not take place till after 2 year, i.e.in 2014, total of 662 cases were reported with a case-fatality rate of $32.97 \% .{ }^{6}$ In the following 02 years, between 2014 and 2016, around 1364 patients were reported in Saudi Arabia. At that point of time, 27 countries were affected by MERS during the outbreak. Since 2012, approximately 2494 laboratory cases of MERS have been observed with around 858 death linked with it, having case-fatality ratio of about $34.4 \%{ }^{7}$

Inadequacy of risk assessment of the novel COVID-19 led to the spread of the virus. Currently, the novel COVID-19 has been labeled to surpass the SARS in terms both the number of cases as well the number of deaths caused by the virus. ${ }^{8}$ Closing live animal markets not only in China but all over might help in decreasing the likelihood of another zoonotic outbreak from occurring. After confirmation of human-to-human transmission, one of the most effective ways to stop the spread of virus is to limit human to human contact as much as possible along with limiting travelling, proper sanitizing and washing etc. ${ }^{9}$ Since in the outbreaks of SARS and MERS, $21 \%$ and $18.6 \%$ of health care workers were reported to acquire the disease, hence the knowledge, safety and protection of health care workers need utmost importance in not only helping to treat the patients but also stop the spread of the pandemic COVID-19. ${ }^{10}$

The coronavirus is identified as a pathogen belonging to novel enveloped RNA betacoronavirus, which is named as severe acute respiratory syndrome coronavirus 2 (SARSCoV-2) that is phylogenetically similar to SARSCoV. ${ }^{11}$ A case of Covid-19 is confirmed as positive on real-time reverse transcriptase-polymerase chain reaction (RT-PCR) assays of both nasal and pharyngeal swab specimens. ${ }^{12}$

The objective of this study was to assess the knowledge of the novel coronavirus (COVID-19) among health care workers working at a secondary care hospital of Karachi, Pakistan.

\section{MATERIAL \& METHODS}

This cross-sectional, observational study using consecutive sampling technique was carried out with study population being the health careworkers including, doctors (consultant and physicians), paramedical staff (nurses, technicians and wardcleaners) working at a secondary care hospital. The hospital is a secondary care center providing both out-patient and in-patient facilities but overall has limited facilities. After ethical approval from the IRB of the hospital, data collection was done from $13^{\text {th }}$ March 2020 to $21^{\text {st }}$ March 2020. A total of 150 participants including 60 doctors and 90 nurses and paramedical staff were included in the study. Before collecting information from the workers, an informed consent was sought with anonymity and confidentiality being maintained. Questionnaire was made by primary authors and administered to the health care workers. The questionnaire was developed for assessing knowledge of health care workers regarding the novel coronavirus pandemic. Knowledge about coronavirus, its effect were recorded and tabulated. Inclusion of workers above 18 years of age of either gender present in-between the study time period and willing to participate in the study were included after explaining them the objectives of the study and that their inclusion will be kept anonymous and confidential. Workers unwilling to participate in the study were excluded. The participants were divided into two groups, one representing doctors or consultants and the other including nurses, paramedical staff and other health care workers. A total of 150 health care workers were included in the study out of which 60 were doctors or consultants and 90 were nurses, paramedical staff and other health care workers.

For data analysis, SPSS version 23.0 was used. The responses of the participants were numbered and reported into qualitative variables and expressed as frequency and percentages.

\section{RESULTS}

The study comprised of 60 doctors of which $60 \%$ were females. From 90 nurses and other health 
care workers, male to female ratio was equal, i.e. 1:1. 42 doctors and $33 \mathrm{HCW}$ had working experience of $1-5$ years. All doctors and $87 \%$ of HCW regarded COVID-19 as a problem to the community. $90 \%$ doctors and $80 \% \mathrm{HCW}$ felt their work performance being affected by the novel COVID-19. Almost all study participants agreed that COVID-19 has affected their social and psychological life (Table I).

$30 \%$ doctors and $80 \% \mathrm{HCW}$ regarded that all coronavirus patients experience fever, dry cough, tiredness and difficulty in breathing while $45 \%$ doctors and $13 \% \mathrm{HCW}$ felt these symptoms do not occur in all cases and $25 \%$ doctors and 07 $\% \mathrm{HCW}$ thought these aren't the symptoms of coronavirus. Almost all the participants thought that coronavirus spread through bats and snakes into humans, can spread from human-to-human close contact, mortality is related to co-morbid and extremes of age and that patients of coronavirus need isolation (Table II).

\section{DISCUSSION}

Since the novel COVID-19 has become a global pandemic, the knowledge and practice of health care workers must be better in all aspects regarding the disease. It is important to know the sign and symptoms of the disease so that when such cases present, not only doctors but other HCWs can also identify, isolate the patients and keep themselves protected from the patients. ${ }^{13}$ In our study, all doctors as well as majority of the HCWs deemed COVID-19 to be problematic for the community, affecting their performances at work, social life as well as psychological life.

\begin{tabular}{|c|c|c|c|}
\hline \multicolumn{2}{|r|}{ Variables } & \multirow{2}{*}{$\begin{array}{c}\text { Doctors } n=60 \\
24(40 \%)\end{array}$} & \multirow{2}{*}{$\begin{array}{c}\text { Nurses and other HCW } \mathbf{n = 9 0} \\
\qquad 45(50 \%)\end{array}$} \\
\hline Gonder & Male & & \\
\hline Geriver & Female & $36(60 \%)$ & $45(50 \%)$ \\
\hline Years of Experience & $1-5$ years & $42(70 \%)$ & $33(37 \%)$ \\
\hline \multicolumn{2}{|c|}{ Do you think COVID-19 is a problem in our community } & $60(100 \%)$ & 78 (87\%) \\
\hline \multicolumn{2}{|c|}{ Has COVID-19 affected your social life } & $60(100 \%)$ & $80(100 \%)$ \\
\hline \multicolumn{2}{|c|}{ Has COVID-19 affected your psychological life } & $60(100 \%)$ & $81(90 \%)$ \\
\hline
\end{tabular}

Table-I. Demographics of study participants

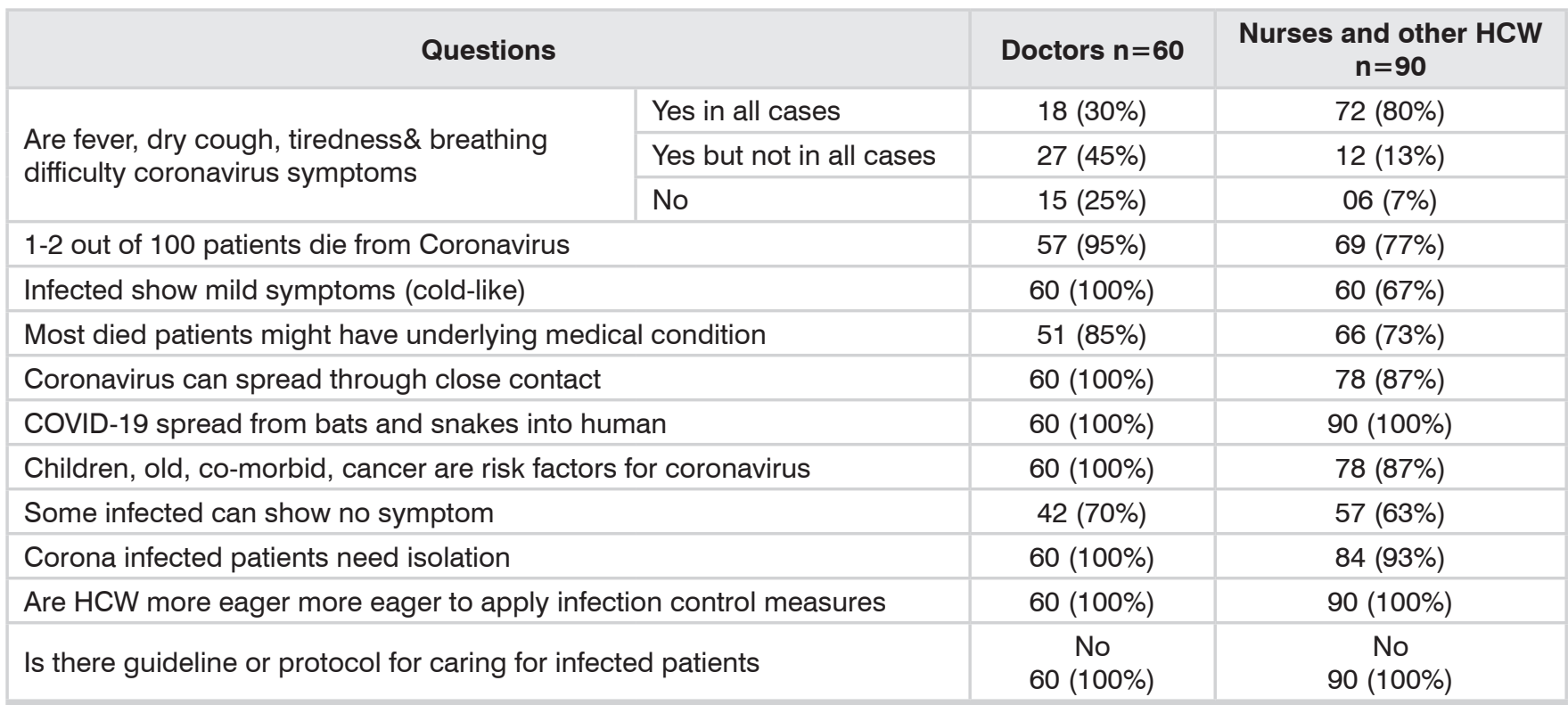

Table-II. Knowledge about the Novel Coronavirus 
Most of the doctors and HCWs correctly identified the sign and symptoms of coronavirus, with the chances of severity and fatality increasing with co-morbid condition and that most COVID-19 patients that die must have an underlying health condition. All participants regarded COVID-19 to spread from bats and cats into human and that human to human close contact increases the spread of the disease. All participants reported that children, senile, co-morbid and cancer patients were at a higher risk for coronavirus and they specifically need isolation.

The most important aspect of the study was that all doctors as well as health-care workers were eager to learn more about the application of infection control measures since currently no guideline or protocol exists for caring of coronavirus patients. According to the WHO, patient having severe acute respiratory infection i.e. cough, fever requiring hospital admission to the hospital and with no other known or diagnosed cause which completely explains the clinical presentation and history of either travel or contact with any travelling person in last 14 days must be considered as a case of coronavirus until proven otherwise. ${ }^{14}$ However the confirmation of coronavirus is done by laboratory investigation for COVID-19 infection, even if a person doesn't show any sign or symptom. ${ }^{15}$ Nonetheless, due to the unavailability or limited resources for detecting coronavirus, even without laboratory confirmation, a person must be isolated and treated as a coronavirus patients when signs and symptoms along with clinical examination points towards coronavirus infection. ${ }^{16}$ The current knowledge of COVID-19 is limited in terms of its exact mode of transmission. Human to human transmission has been confirmed and though to spread via respiratory droplets either by sneezing or coughing. ${ }^{17}$ Although the primary COVID-19 cases have been traced back to the Huanan sea food market, however secondary cases were still reported in hospitals amongst physicians as well as nurses which had come in contact with the coronavirus patients. Nonetheless, multiple cases were also reported which did not report any direct contact with individuals from the seas food market that had contracted the disease. ${ }^{18}$
Spread of infection is mostly thought to be from respiratory droplets or secretions of the infected patients, pre-dominantly being transmitted from human-to-human. When the initial reports of coronavirus COVID-19 were analyzed, $73 \%$ were males, with $32 \%$ having co-morbid including hypertension, diabetes and cardiovascular disease with a mean age of 49 years. Amongst them, $66 \%$ of patients had a history of visiting the Huanan sea food market. ${ }^{19}$

The current COVID-19 possesses several challenges to not only the health care industry, but also to the stakeholders and governmental policy makers to not only provide the health care setups with proper facilities, protection and ensure the patients are taken care of in the most perfect manner. Lack of knowledge, lack of medical supplies, inadequate laboratory and isolation facilities are a barrier in fighting against COVID-19. ${ }^{20}$

\section{LIMITATIONS AND RECOMMENDATIONS}

One of the major limitations of the study was that the study was health care worker based and not patients based which would have helped in providing more accurate information. Other limitations included a limited sample size, recall and selection bias. Being the first in line of duty to manage COVID-19 patients it is vital to provide guideline in addition to safety measures for ensuring proper treatment and limit spread of disease.

\section{CONCLUSION}

Most doctors and health care workers were aware about the signs and symptoms of coronavirus disease. Most doctors were also aware of the knowledge regarding the novel COVID-19, however many health care workers were not fully aware of the consequences and effects of coronavirus.

Copyright $\odot 19$ Sep, 2020.

\section{REFERENCES}

1. Zhu N, Zhang D, Wang W, Li X, Yang B, Song J, et al. Brief Report: A Novel Coronavirus from Patients with Pneumonia in China, 2019. The New England Journal of Medicine. 2020 Feb 20; 382(8):727-33. 
2. Huang C, Wang $Y$, Li X, Ren L, Zhao J, Hu Y, et al. Clinical features of patients infected with 2019 novel coronavirus in Wuhan, China. The Lancet. 2020 Feb 15; 395(10223):497-506.

3. de Wit E, van Doremalen N, Falzarano D, Munster VJ. SARS and MERS: Recent insights into emerging coronaviruses. Nature Reviews Microbiology. 2016 Aug; 14(8):523-34.

4. World Health Organization. Coronavirus disease 2019 (COVID-19): situation report, 72.

5. Anderson RM, Fraser C, Ghani AC, Donnelly CA, Riley $\mathrm{S}$, Ferguson NM, et al. Epidemiology, transmission dynamics and control of SARS: the 2002-2003 epidemic. Philosophical Transactions of the Royal Society of London. Series B: Biological Sciences. 2004 Jul 29; 359(1447):1091-105.

6. Mackay IM, Arden KE. MERS coronavirus: Diagnostics, epidemiology and transmission. Virology journal. 2015 Dec; 12(1):222-43.

7. Al-Omari A, Rabaan AA, Salih S, Al-Tawfiq JA, Memish ZA. MERS coronavirus outbreak: Implications for emerging viral infections. Diagnostic microbiology and infectious disease. 2019 Mar 1; 93(3):265-85.

8. Liu Y, Gayle AA, Wilder-Smith A, Rocklöv J. The reproductive number of COVID-19 is higher compared to SARS coronavirus. Journal of Travel Medicine. 2020 Mar; 27(2):1-6.

9. Wilder-Smith A, Chiew CJ, Lee VJ. Can we contain the COVID-19 outbreak with the same measures as for SARS? Lancet Infect Dis. 2020 May;20(5):e102-e107. doi: 10.1016/S1473-3099(20)30129-8. Epub 2020 Mar 5. PMID: 32145768; PMCID: PMC7102636.

10. Alsahafi AJ, Cheng AC. Knowledge, attitudes and behaviours of healthcare workers in the Kingdom of Saudi Arabia to MERS coronavirus and other emerging infectious diseases. International journal of environmental research and public health. 2016 Dec; 13(12):1214-22.

11. Lai CC, Shih TP, Ko WC, Tang HJ, Hsueh PR. Severe acute respiratory syndrome coronavirus 2 (SARSCoV-2) and corona virus disease-2019 (COVID-19): The epidemic and the challenges. International journal of antimicrobial agents. 2020 Feb 17:105924.
12. Tang YW, Schmitz JE, Persing DH, Stratton CW. Laboratory diagnosis of COVID-19: Current issues and challenges. Journal of clinical microbiology. 2020 May 26; 58(6):1-9.

13. Peeri NC, Shrestha N, Rahman MS, Zaki R, Tan Z, Bibi $S$, et al. The SARS, MERS and novel coronavirus (COVID-19) epidemics, the newest and biggest global health threats: What lessons have we learned?. International journal of epidemiology. 2020 Feb 22.

14. Bai Y, Yao L, Wei T, Tian F, Jin DY, Chen L, et al. Presumed Asymptomatic Carrier Transmission of COVID-19. JAMA-Journal of the American Medical Association. 2020 Jan 1.

15. Rothan HA, Byrareddy SN. The epidemiology and pathogenesis of coronavirus disease (COVID-19) outbreak. Journal of autoimmunity. 2020 Feb 26:102433-7.

16. Palm D, Pereyaslov D, Vaz J, Broberg E, Zeller H, Gross D, et al. Laboratory capability for molecular detection and confirmation of novel coronavirus in Europe, November 2012. Eurosurveillance. 2012 Dec $6 ; 17(49): 20335-9$.

17. Guo YR, Cao QD, Hong ZS, Tan YY, Chen SD, Jin HJ, et al. The origin, transmission and clinical therapies on coronavirus disease 2019 (COVID-19) outbreak-an update on the status. Military Medical Research. 2020 Dec; $7(1): 1-0$.

18. Sohrabi C, Alsafi Z, O’Neill N, Khan M, Kerwan A, Al-Jabir $A$, et al. World Health Organization declares global emergency: A review of the 2019 novel coronavirus (COVID-19). International Journal of Surgery. 2020 Feb 26.

19. Chen N, Zhou M, Dong X, Qu J, Gong F, Han Y, et al. Epidemiological and clinical characteristics of 99 cases of 2019 novel coronavirus pneumonia in Wuhan, China: A descriptive study. The Lancet. 2020 Feb 15; 395(10223):507-13.

20. Arabi YM, Murthy S, Webb S. COVID-19: A novel coronavirus and a novel challenge for critical care. Intensive care medicine. 2020 Mar 3:1-4. 


\section{AUTHORSHIP AND CONTRIBUTION DECLARATION}

\begin{tabular}{|c|l|l|l|}
\hline Sr. \# & \multicolumn{1}{|c|}{ Author(s) Full Name } & \multicolumn{1}{|c|}{ Contribution to the paper } & Author(s) Signature \\
\hline 1 & Rashida Riaz & $\begin{array}{l}\text { Conception and design of } \\
\text { study. }\end{array}$ \\
\hline 3 & Ahmed Mujtaba Memon & $\begin{array}{l}\text { Conception and design of } \\
\text { study. } \\
\text { Final approval for version. }\end{array}$ \\
\hline 5 & Fareha Kashan Theba & Final approval for version. \\
6 & Zohra Jabeen & $\begin{array}{l}\text { Data analysis write up and } \\
\text { proof reading. } \\
\text { Data analysis and write up. }\end{array}$
\end{tabular}

